\section{6} OPEN ACCESS

\title{
Treating axial spondyloarthritis and peripheral spondyloarthritis, especially psoriatic arthritis, to target: 2017 update of recommendations by an international task force
}

\author{
Josef S Smolen, ${ }^{1,2}$ Monika Schöls, ${ }^{3}$ Jürgen Braun, ${ }^{4}$ Maxime Dougados, ${ }^{5}$ \\ Oliver FitzGerald, ${ }^{6}$ Dafna D Gladman, ${ }^{7}$ Arthur Kavanaugh, ${ }_{1}^{8}$ Robert Landewé, ${ }^{9}$ \\ Philip Mease, ${ }_{1}^{10}$ Joachim Sieper, ${ }_{1}^{11}$ Tanja Stamm, ${ }^{12}$ Maarten de Wit, ${ }_{13}^{13}$ Daniel Aletaha, \\ Xenofon Baraliakos, ${ }^{4}$ Neil Betteridge ${ }^{14}$ Filip van den Bosch, ${ }^{15}$ Laura C Coates, ${ }^{16}$ \\ Paul Emery, ${ }^{17}$ Lianne S Gensler, ${ }^{18}$ Laure Gossec, ${ }^{19}$ Philip Helliwell, ${ }^{20}$ Merryn Jongkees, ${ }^{21}$ \\ Tore K Kvien, ${ }^{22}$ Robert D Inman, ${ }^{23}$ Iain B McInnes, ${ }^{24}$ Mara Maccarone, ${ }_{1,28}$ \\ Pedro M Machado, ${ }^{26}$ Anna Molto, ${ }^{5}$ Alexis Ogdie, ${ }^{27}$ Denis Poddubnyy, ${ }_{1}^{11,28}$ \\ Christopher Ritchlin, ${ }^{29}$ Martin Rudwaleit, ${ }^{11,30}$ Adrian Tanew, ${ }_{1}^{31}$ Bing Thio, ${ }^{32}$ \\ Douglas Veale, ${ }^{33}$ Kurt de Vlam, ${ }^{34}$ Désirée van der Heijde ${ }^{35}$
}

\begin{abstract}
- Additional material is published online only. To view, please visit the journal online (http://dx.doi.org/10.1136/ annrheumdis-2017-211734).

For numbered affiliations see end of article.
\end{abstract}

\section{Correspondence to} Josef S Smolen, Division of Rheumatology, Department of Medicine 3,Medical University of Vienna, Waehringer Guerte 19-20, 1090 Vienna, Austria; josef.smolen@wienkav.at

Received 4 May 2017 Revised 5 June 2017 Accepted 5 June 2017 Published Online First 25 October 2017

\section{CrossMark}

\section{ABSTRACT}

Therapeutic targets have been defined for axial and peripheral spondyloarthritis (SpA) in 2012, but the evidence for these recommendations was only of indirect nature. These recommendations were re-evaluated in light of new insights. Based on the results of a systematic literature review and expert opinion, a task force of rheumatologists, dermatologists, patients and a health professional developed an update of the 2012 recommendations. These underwent intensive discussions, on site voting and subsequent anonymous electronic voting on levels of agreement with each item. A set of 5 overarching principles and 11 recommendations were developed and voted on. Some items were present in the previous recommendations, while others were significantly changed or newly formulated. The 2017 task force arrived at a single set of recommendations for axial and peripheral SpA, including psoriatic arthritis (PsA). The most exhaustive discussions related to whether PsA should be assessed using unidimensional composite scores for its different domains or multidimensional scores that comprise multiple domains. This question was not resolved and constitutes an important research agenda. There was broad agreement, now better supported by data than in 2012, that remission/ inactive disease and, alternatively, low/minimal disease activity are the principal targets for the treatment of PsA. As instruments to assess the patients on the path to the target, the Ankylosing Spondylitis Disease Activity Score (ASDAS) for axial SpA and the Disease Activity index for PSoriatic Arthritis (DAPSA) and Minimal Disease Activity (MDA) for PsA were recommended, although not supported by all. Shared decision-making between the clinician and the patient was seen as pivotal to the process. The task force defined the treatment target for SpA as remission or low disease activity and developed a large research agenda to further advance the field.

\section{INTRODUCTION}

Recommendations on general treatment targets in spondyloarthritis (SpA) and the strategy to treat
SpA to these targets were developed in 2012 by an international task force. ${ }^{1}$ These recommendations are deliberately generic and intended to inform the optimal treatment approach rather than advise around a specific drug entity, since it was deemed important to develop and describe a conceptual framework independent of particular drug availability or preference. Other groups have focused on drug therapies in management recommendations for axial SpA and psoriatic arthritis $(\mathrm{PsA})^{2-4}$; two of the three management recommendations adopted the treat-to-target (T2T) concept. ${ }^{24}$ This concept, originally developed for chronic diseases such as diabetes, ${ }^{5}$ has already been successfully implemented for rheumatoid arthritis (RA). ${ }^{6}$ Systematic literature reviews (SLRs) underpinning the T2T recommendations for RA revealed data from several trials with efficacy of a target-driven therapeutic approach as superior to usual clinical care in RA for clinical, functional and structural outcomes. ${ }^{78}$ The 2012 task force applied this concept to SpA, despite the fact that the SLR on the original T2T recommendations for $\mathrm{SpA}$ revealed only indirect evidence favouring this approach, given the absence of data from strategic clinical trials.

All recommendations developed in 2012 for SpA treatment to target were based on evidence levels of the lowest category ${ }^{1}$ (category 5), ${ }^{10}$ which derives solely from expert opinion, even if they were based on several lines of indirect evidence. Therefore, an ambitious research agenda was then proposed to focus on improving the definition of treatment targets and validating respective instruments and emphasised the importance of data collection from strategic clinical trials. The participants understood such limitations and in the manuscript it was stated at the time that 'given the small evidence base, the research agenda is of utmost importance', anticipating a revision of the document 'in about 4 years or 5 years..., when significant evidence accumulates regarding the individual points of the 
recommendations' that 'either allow confirmation or modifications' of the conclusions. ${ }^{1}$

Subsequently, in line with those expectations, a number of publications in the field have addressed several points raised in the research agenda. Therefore, our objective was to re-evaluate and update the recommendations.

\section{METHODS}

At the beginning of this endeavour, a steering committee (SC) comprising rheumatologists from Europe and North America experienced in SpA clinical research, a patient and a health professional (in total 13 members) was convened in August 2016 in Vienna, Austria, by a rheumatologist (JSS) and a methodologist $(\mathrm{DvdH})$ to discuss the potential need for a recommendation update based on the information available from the literature published in recent years. Research questions for an update of the systematic literature review (SLR) ${ }^{9}$ were formulated by the SC members; the process adhered to the updated European League Against Rheumatism (EULAR) standard operating procedures (SOPs) for developing recommendations. ${ }^{11}$ The SLR, which was performed by MS and covered the period from the last SLR (2011) to the end of 2016 is summarised in the online supplementary material A. It was presented at a 2-day meeting in March 2017 in Düsseldorf, Germany. The detailed SLR was reported to the SC. The SC then carefully reviewed every item of the overarching principles and recommendations developed in 2012 and proposed an amended set of recommendations for discussion by the whole task force.

The next day, the task force comprising 36 members was convened (one additional expert, TKK, was involved in the planning of the activity and in the level of agreement voting and manuscript development process). Among these members were four patient representatives (NB, MJ, MM, MdW), 1 (nonMD) health professional (TS), 2 dermatologists (AT, BT) and 28 rheumatologists, 6 of whom came from North America with the remainder coming from Europe. All experts had a significant publication record in the field of SpA. Indeed, several of the experts are also committee members of the Group for Research and Assessment of Psoriatic Arthritis (GRAPPA; www.grappanetwork.org/committee-list) and coauthors of the 2015 GRAPPA PsA treatment recommendations; another group of experts is involved in Assessment of SpondyloArthritis international Society (ASAS) activities (http://asas-group.org/committee.php) and participated in the development of the ASAS-EULAR axial SpA management recommendations ${ }^{4}$ and a third group has been involved in the generation of the EULAR PsA management recommendations, ${ }^{2}$ with some small overlap among these involvements.

In line with the SOPs, no representative of the company providing the unrestricted grant was present to avoid any potential influence on the discussion or development of the recommendations; this position has been and still is a general principle throughout all T2T activities.

At the beginning, the convenor summarised the 2012 recommendations together with the 2012 discussions. In particular, the 2012 task force had originally contemplated developing three sets of recommendations, namely one for axial SpA, one for peripheral SpA excluding PsA and one for PsA. During the 2012 process, it became apparent that the three proposed sets had significant overlap such that the final recommendations comprised a common trunk of five overarching principles and nine recommendations, as well as two recommendations each for axial SpA, PsA and peripheral SpA.
Given the recent proliferation of instruments (categorical and continuous) for evaluating the multiple domains of PsA, ${ }^{12}$ one of the SC members (OF) presented a summary of these measures to the task force. The methodologist $(\mathrm{DvdH})$ addressed the scientific and methodological background of selecting components of composite indices for chronic rheumatic diseases.

An abbreviated version of the SLR was then presented to the task force (MS) with residual information available on request. Of note, very few data exist for peripheral SpA and, therefore, in line with the results of the SLR, the current activity focused on axial $\mathrm{SpA}$ and PsA.

For the discussion and decision-making process of the recommendations, each item of the 2012 version was shown together with the SC proposal for the new version. Each of the items was subjected to a thorough discussion in light of the evidence presented and to a rigorous voting process. The methodologist explained that, as in the previous and similar endeavours, ${ }^{14} 13$ the initial ballot required at least $75 \%$ of votes to accept a proposal for a recommendation. If this result was not achieved, textual amendments were discussed and in the next round $67 \%$ of the votes were needed. If that amendment was not sufficient, the process continued and then a member vote of $>50 \%$ was needed for approval and acceptance.

The level of evidence (LoE) and strength or recommendation (SoR) was based on the Oxford Evidence-Based Medicine categorisation. ${ }^{10}$

After the meeting, the newly formulated recommendations were compiled in a single table together with the LoE, SoR and voting results at the meeting. All task force members assigned electronically (by email) and anonymously level of agreement (LoA) with each item on a scale of 0 (no agreement at all) to 10 (full agreement).

\section{RESULTS}

\section{General aspects}

Implementation, feasibility and validity

A central question, mentioned by the convenor in his introductory remarks, concerned the implementation of the previous recommendations. Implementation may be supported by the fact that both EULAR PsA and ASAS-EULAR axial SpA management recommendations have adopted the T2T approach. The $\mathrm{T} 2 \mathrm{~T}$ recommendations for RA were also strongly integrated into the respective American College of Rheumatology (ACR) and EULAR management guidance documents. ${ }^{13} 14$ Nevertheless, implementation is often impeded in clinical practice. ${ }^{15}$ Learning collaboratives, that is, group-based multisite educational collaboratives, can be successful in this respect. ${ }^{16}$

In some practice settings, effective implementation is attained when rheumatologists have to enter detailed data into registries. ${ }^{17}$ However, even if rheumatologists agree with certain principles, the practical application of these principles may be limited. ${ }^{18} \mathrm{~A}$ recent survey revealed that 'a busy clinical practice, accompanied by a shortage of supporting staff, was identified as the main barrier to full compliance with the T2T recommendations from the physician standpoint'. ${ }^{19}$ Indeed, 'limitations arise as a result of ... lack of time for the individual patient with RA', ${ }^{20}$ despite the fact that the T2T-RA recommendations only call for using a composite measure for RA disease activity that includes joint counts. ${ }^{1}$ Since T2T recommendations are developed primarily for clinical practice, feasibility should be a major characteristic, among others, in line with the Appraisal of Guidelines for Research and Evaluation II guidelines, which call for applicability and consideration of resource implications when developing 
recommendations. ${ }^{22}$ In other words, a measure is feasible when it can 'be applied easily, given constraints of time, money or interpretability' despite the complexity of its development. ${ }^{23}$ In addition, the composite 'measure must discriminate between situations of interest', be truthful, that is, have face, construct, content and criterion validity and demonstrate reliability. ${ }^{23}$ Notably, health professionals in rheumatology may support the implementation and practice of $\mathrm{T} 2 \mathrm{~T}$ recommendations.

\section{Instruments for PsA}

In the presentation on the measures used for PsA assessment, several different instruments, their components and calculations were addressed and are shown in table 1. They comprise the Composite Psoriatic Disease Activity Index (CPDAI), ${ }^{24}$ Disease Activity index for PSoriatic Arthritis (DAPSA), ${ }^{25}$ GRAppa Composite Exercise (GRACE) index, ${ }^{26}$ Minimal Disease Activity (MDA) ${ }^{27}$ and Psoriatic Arthritis Disease Activity Score (PASDAS). ${ }^{12}$ Most of these instruments allow calculation of continuous scores, while one (MDA) is dichotomous or categorical. The continuous scales can also be applied to define disease activity categories or states. One measure focuses only on joint activity (DAPSA), the others also include measures of other (non-articular) musculoskeletal domains (such as enthesitis and axial disease), skin manifestations, physical functioning or quality of life (table 1).

\section{Selection of domains for composite measures of disease activity}

The presentation on the selection of components for composite disease activity measures focused on axial SpA. Issues of methodological rigour, instrument properties pertaining to composite measures and the preference of a unidimensional approach to disease activity assessment were discussed. ${ }^{28}$ Additionally, the concern of combining domains into a composite that may not track together, particularly regarding response to therapy, was addressed, since the risk increases of missing true improvement in individual domains, or missing non-response or deterioration in other domains. Moreover, in this situation a good performance of one dimension can 'compensate' for a bad result in another dimension despite being different disease manifestations. This may not be the case when the disease domains are assessed separately with respective validated instruments. For example, uveitis occurs frequently in patients with axial SpA (>20\%) and concomitant psoriasis or inflammatory bowel disease (IBD) are not rare. ${ }^{29}{ }^{30}$ However, uveitis activity $^{31}$ since relating to a different domain should not be part of an index for axial SpA.

It was also noted that composites should not combine a measure of inflammation with a measure of structural changes or physical functional, since damage and function are different constructs than activity. While they are partly a consequence of the inflammatory process, they do not reflect this process directly (figure 1). Furthermore, when outcome measures are combined with activity measures, the ability to detect improvement might preclude a subgroup of patients with long-standing disease from achieving remission despite experiencing clear-cut absence of inflammation. ${ }^{32-35}$ Moreover, when the data from these instruments are correlated with physical function as an outcome, circular reasoning may ensue. Therefore, ASAS improvement and partial remission criteria, which include function (table 2), ${ }^{36}$ are less discriminative and appropriate than the respective Ankylosing Spondylitis Disease Activity Score (ASDAS) categories. ${ }^{37}$

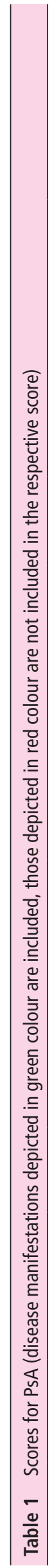



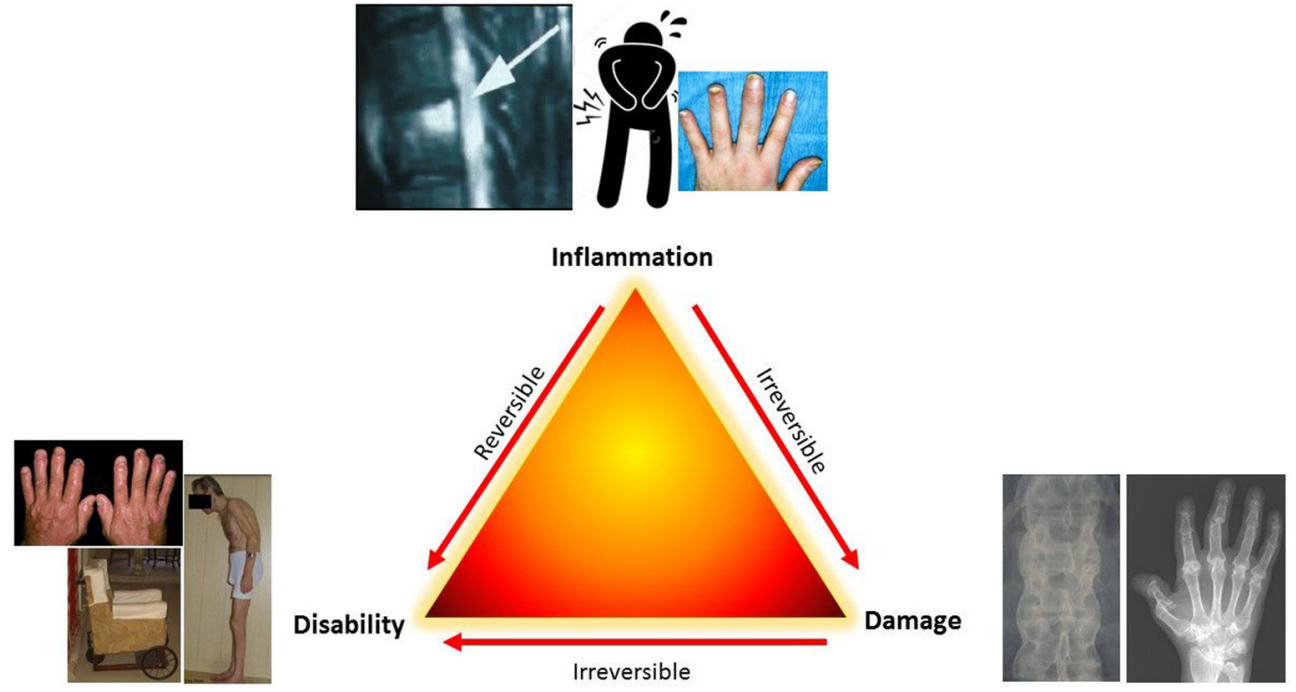

Figure 1 Relationships between inflammation, damage and disability. Inflammation, by virtue of pain and stiffness, elicits disability which is reversible on reversal of disease activity. Inflammation also induces damage which is usually irreversible. Damage also induces disability; due to its irreversible nature, damage-induced disability is irreversible, meaning that with increasing damage the floor of physical functioning that can be reached on reversal of disease activity rises.

In general, composite measures have the advantage of encompassing various aspects linked to a construct, such as inflammation. For example, in RA and also PsA joint swelling and acute phase reactant (APR) levels are more strongly associated with progression of joint damage, than joint tenderness, ${ }^{38-41}$ patient global and pain assessments, while the latter are more strongly associated with disability than damage; a composite measure that combines these individual variables reflecting current disease activity will, therefore, relate to the totality of future adverse disease outcomes. ${ }^{42-44}$ Of note, the term 'outcome' is frequently used interchangeably with the term 'end point' (of an intervention, ie, outcome of a treatment or a study), while here it will be used primarily to reflect the sequel of diseases like axial SpA and PsA.

A number of task force members believe that in PsA, as a multidimensional disease, one should be aiming to measure psoriatic disease as a construct and, therefore, the instrument needed to combine individual domains into a single 'snapshot' of the disease; moderate disease activity in several domains may altogether contribute to a single score representing high disease activity and response criteria and cut-offs will reflect the disease as a whole. Others are of the opinion that especially in a multidimensional disease unidimensional scoring of the individual components is pivotal to understand the heterogeneity in an individual patient and especially therapeutic effects on the individual domains. By this reasoning all disease manifestations should be assessed, but separately and not within one index (a unidimensional approach). Indeed, just like in RA or axial SpA, where management recommendations relate to the respective levels of disease activity, ${ }^{4} 1314$ the most recent management recommendations for PsA relate to the level of activity of the individual domains and not a total score of psoriatic disease. ${ }^{23}$ It is also noteworthy that the recent approvals by regulatory authorities of all novel therapies for PsA were based on clinical trials using unidimensional primary end points, even though they were derived from RA and were thus not specific for PsA joint involvement nor other manifestations of the disease. While the ACR response criteria include a measure of physical function, it is one of five measures (of which three need to be fulfilled) that can only be used if joint counts improve by a minimum of $20 \%, 50 \%$ or $70 \% .{ }^{45}$ In post hoc subanalyses, however, several of the newer composite scores such as PASDAS were evaluated ${ }^{26}$ and newer trials are including composite multidimensional measures related to all domains and/or the unidimensional DAPSA as key outcomes.

During the meeting and in the process of developing the manuscript, no clear agreement emerged between these two schools of thought. Most of the participants who advocated multidimensional scores were members of GRAPPA committees, while most of those advocating unidimensional scoring approaches were not. Thus, it appears that this is still an area of research that needs to be growing and methods of defining validity are developing. ${ }^{46} 47$ To this end, several ongoing studies are aiming to further define the optimal outcome measures for PsA.

\section{THE CONSENSUS}

\section{Overarching principles}

Providing a framework to embed the individual recommendations was important. Such a framework has been studied rarely in a methodological fashion. Therefore, the previous document already included 'principles' that govern and underscore the realisation of the recommendations. ${ }^{1}$ The current task force adhered to this approach and agreed on five overarching principles, in line with the 2012 recommendations.

A. The treatment target must be based on a shared decision between patient and rheumatologist. This first principle remained unchanged. It is fundamental to good clinical practice and constitutes a quality indicator of patient care in other diseases. ${ }^{48}$ There was discussion whether the term 'target' should be changed to 'targets', because SpA exhibits clinical heterogeneity and patients and rheumatologists wish to achieve the treatment target across disease domains, whether musculoskeletal or extramusculoskeletal. A counterargument addressed the point that the singular 'target', which focuses on a state to be attained, pertains to the outcome of all domains. Furthermore, 'treatment targets' is a term that is rarely, if ever used and might require 
Table 2 Clinical assessment of axial spondyloarthritis

\begin{tabular}{|c|c|c|}
\hline BASDAI $^{62}$ & Questions & Calculation \\
\hline & $\begin{array}{l}\text { 1. How would you describe the overall level of fatigue/tiredness you have } \\
\text { experienced? }\end{array}$ & \multirow{6}{*}{$\begin{array}{l}\text { Assess each question on a numerical rating scale (NRS) of } 0 \text { (none } \\
\text { to } 10 \text { (very severe), alternatively, a VAS can be used for questions } \\
1-5 \text { (NRS preferred by ASAS) } \\
\text { Calculation of BASDAl: } \\
\text { Compute the mean of questions } 5 \text { and } 6 \\
\text { Calculate the sum of the values of question } 1-4 \text { and add the } \\
\text { result to the mean of questions } 5 \text { and } 6 \\
\text { Divide the result by } 5\end{array}$} \\
\hline & $\begin{array}{l}\text { 2. How would you describe the overall level of ankylosing spondylitis neck, } \\
\text { back or hip pain you have had? }\end{array}$ & \\
\hline & $\begin{array}{l}\text { 3. How would you describe the overall level of pain/swelling in joints other } \\
\text { than neck, back or hips you had? }\end{array}$ & \\
\hline & $\begin{array}{l}\text { 4. How would you describe the overall level of discomfort you have had from } \\
\text { any areas tender to touch or pressure? }\end{array}$ & \\
\hline & $\begin{array}{l}\text { 5. How would you describe the overall level of morning stiffness you have had } \\
\text { from the time you wake up? }\end{array}$ & \\
\hline & 6. How long does your morning stiffness last from the time you wake up? & \\
\hline \multirow[t]{7}{*}{ ASDAS $^{84} 89$} & Parameters & Calculations \\
\hline & 1. Total back pain (BASDAl question 2) & \multirow{6}{*}{$\begin{array}{l}\text { ASDAS-CRP: } 0.121 \times \text { total back pain }+0.110 \times \text { patient } \\
\text { global }+0.073 \times \text { peripheral pain/swelling }+0.058 \times \text { duration } \\
\text { of morning stiffness }+0.579 \times \ln (C R P+1) ; A S D A S-E S R \text { : } \\
0.113 \times \text { patient global }+0.293 \times \sqrt{E S R}+0.086 \times \text { peripheral pain/ } \\
\text { swelling }+0.069 \times \text { duration of morning stiffness }+0.079 \times \text { xtotal back } \\
\text { pain } \\
\text { Assess each question on an NRS of } 0 \text { (none) to } 10 \text { (very severe) }\end{array}$} \\
\hline & 2. Patient global assessment & \\
\hline & 3. Peripheral pain/swelling (BASDAI question 3) & \\
\hline & 4. Duration of morning stiffness (BASDAl question 6) & \\
\hline & 5. C reactive protein (CRP) in mg/L (or erythrocyte sedimentation rate (ESR)) & \\
\hline & (the lowest value for CRP can be $2 \mathrm{mg} / \mathrm{L}$ ) & \\
\hline
\end{tabular}

Improvement criteria

ASAS $20^{90}$

Improvement $\geq 20 \%$ and absolute improvement of $\geq 1$ unit (on a scale of

$0-10$; or 10 units on a scale of $0-100$ ) in at least three of the four following domains:

Patient global assessment

Pain

Function (BASFI) ${ }^{63}$

Inflammation (mean of morning stiffness-related BASDAI VAS scores for questions 5 and 6 )

No worsening of $\geq 20 \%$ and $\geq 1$ unit in the remaining domain

ASAS $40^{91} \quad$ Improvement $\geq 40 \%$ and absolute improvement of $\geq 2$ unit (on a scale of

$0-10$; or 10 units on a scale of $0-100$ ) in at least three of the four following domains:

Patient global assessment

Pain

Function (BASFI) ${ }^{63}$

Inflammation (mean of morning stiffness-related BASDAI VAS scores for questions 5 and 6 )

No worsening at all in the fourth domain

\section{Remission criteria}

ASAS partial remission ${ }^{90}$

A value not above two units on a $0-10$ scale in each of the four domains: patient global, pain, function, inflammation (mean of morning stiffnessrelated BASDAI VAS scores for questions 5 and 6$)^{*}$

ASDAS inactive disease $^{84} \quad$ ASDAS $<1.3$

ASAS, Assessments of SpondyloArthritis international Society ${ }^{90}$; ASDAS, Ankylosing Spondylitis Disease Activity Score; BASDAl, Bath Ankylosing Spondylitis Disease Activity Index ${ }^{62}$; BASFI, Bath Ankylosing Spondylitis Functional Index; VAS, Visual Analogue Scale.

clarification for patients and rheumatologists. The patients felt strongly about the need for physicians to adhere to evidence-based therapies and to educate patients on the importance of such therapies versus unproven approaches. While there was broad agreement here, this aspect was felt to be more appropriate for the individual recommendations (to be discussed subsequently) and to drug management guidance documents. In a first ballot, the $75 \%$ majority needed was not obtained; the principle as worded and the original singular version of 'target' then received 69.4\% approval in the second ballot.

B. Treatment to target by measuring disease activity, and adjusting therapy accordingly, improves outcomes. Since the previous version of these recommendations, evidence for the benefit of a T2T strategy compared with routine care has been obtained for PsA in the TICOPA trial. ${ }^{49}$ Therefore, it was proposed to replace the previous wording 'contributes to short-term and/or long-term outcomes' simply by 'improves outcomes'. Although no T2T study has been performed in axial $\mathrm{SpA}$, it was deemed that such an approach could also improve outcomes in axial SpA, given the correlation of damage progression with disease activity. ${ }^{50} 51 \mathrm{~T} 2 \mathrm{~T}$ studies are currently ongoing in axial SpA (eg, TICOSPA, NCT 03043846, and STRIKE, NCT 02897115). In the course of the deliberations, it was mentioned that the efficacy benefit of a T2T approach in PsA was somewhat counterbalanced by more adverse events in the TICOPA trial, ${ }^{49}$ however, this may be related to therapy choice (rapid csDMARD escalation and combinations) and partially due to reporting bias (T2T patients were reviewed every 4 weeks, controls every 12 weeks) rather than the T2T strategy itself. Nevertheless, as will be detailed in the individual recommendations 
and mentioned in principle $\mathrm{C}$, safety aspects have to be considered when using a T2T approach. Thus, it was suggested to mention that for axial SpA this principle should currently be read as 'T2T is based on the assumption that it improves outcomes'. Despite these caveats, the new wording was accepted by a majority of task force members $(83.3 \%)$ in the first ballot.

C. SpA and PsA are multifaceted systemic diseases; the management of musculoskeletal and extra-articular manifestations should be coordinated, as needed, between the rheumatologist and other specialists (such as dermatologists, gastroenterologists, ophthalmologists). The original version: 'SpA and PsA are often complex systemic diseases' was changed in two aspects: first, 'complex' was deemed by some to suggest that these diseases are too complicated to be understood, while it was used in 2012 to address the disease heterogeneity. Various additional aspects, especially concerning the term 'extra-articular manifestations', were discussed and are provided in online supplementary material B. The term 'extra-articular' will refer to nonmusculoskeletal abnormalities, such as the skin or the eye; indeed, current management recommendations separate these domains regarding specific treatment approaches. ${ }^{2} 3$ However, the management recommendations also separate arthritis from other musculoskeletal manifestations; therefore, we will refer to axial disease, dactylitis and enthesitis as 'non-articular musculoskeletal manifestations' for the sake of semantic consistency and differentiation from 'extra-articular' manifestations. Furthermore, replacing 'specialists' by 'specialties' was discussed, but did not find popularity. Finally, it was suggested to expand 'extra-articular' to 'extra-articular and other manifestations' to also account for cardiovascular risk and other comorbidities; however, this also did not find major agreement, since these comorbidities, while serious and to be taken into account when following patients with $\mathrm{SpA}$, constitute primarily consequences of chronic inflammation in general, rather than extra-articular manifestations of the underlying $\mathrm{SpA}$, which are the focus of the current endeavour. Changing 'complex' to 'multifaceted' achieved $100 \%$ approval, maintaining 'specialists' rather than changing to 'specialties' achieved $86 \%$ approval, and leaving 'extra-articular' unchanged attained $69.4 \%$ of votes in a second ballot.

D. The goals of treating the patient with axial SpA or PsA are to optimise long-term health-related quality of life and social participation through control of signs and symptoms, prevention of structural damage, normalisation or preservation of function, avoidance of toxicities and minimisation of comorbidities. Compared with the previous version, the qualification 'primary', in the sense of 'main', for the goal was felt to be confusing, since several goals (and not just one) were mentioned thereafter. Therefore, it was suggested to simply delete 'primary' and replace goal by its plural form. This found an $86 \%$ approval. In a second ballot, the previous term 'maximise' was replaced by 'optimise' (72\%). Discussions on specifying MRI regarding structural damage assessment and mentioning acute phase reactants in the context of this principle were not taken further here and postponed to deliberations on the specific recommendations. Of note and in reference to discussions mentioned above, comorbidities are specifically included here.

E. Abrogation of inflammation is important to achieve these goals. Compared with previous principle D, which stated that 'abrogation of inflammation is presumably important', 'presumably' was now deleted, since sufficient evidence had accumulated over the last 5 years that inflammation is pivotal for progression of damage. ${ }^{3950-52}$ Therefore, even though PsA is not a homogeneous disease and up to one-third of patients may have non-progressive arthritis where this paradigm may not apply, ${ }^{53}$ in the majority of patients, interference with inflammation is needed to achieve good outcomes. It was also suggested to exchange the word 'abrogation' by 'elimination' because this might be better understood; however, reference to the patient version of RA recommendations revealed that this term can be easily transposed for lay people. ${ }^{54}$ There was 94.4\% agreement with the above version in the first ballot.

\section{Recommendations}

The task force next evaluated potential changes to the recommendations. All options were acceptable, namely: to be left as they had originally been constructed, amended, deleted or expanded in number and/or changed in sequence. Adherence to the evidence available was the pivotal driver during this process. The previous recommendations and the proposals for amendment by the SC were presented and discussed. This process resulted in a total of 11 bullet points.

1. The treatment target should be clinical remission/inactive disease of musculoskeletal (arthritis, dactylitis, enthesitis, axial disease) and extra-articular manifestations. This bullet point previously read: 'A major treatment target should be clinical remission/inactive disease of musculoskeletal involvement (arthritis, dactylitis, enthesitis, axial disease), taking extra-articular manifestations into consideration'. Thus, from the perspective of the content, the updated recommendation remained similar, but it was shortened and a few items deleted. For example, it was not deemed necessary to call the target a 'major' one, since remission should be the aim in essentially all patients, while the term 'should' inherently suggests that this may not always be achievable (see item 4). Also, the phrase 'taking extra-articular manifestations into consideration' already suggested that their reversal should be accounted for. Importantly, however, no clinical trial used remission or inactive disease as a target for a strategic trial. The only strategic trial currently published focused on MDA, which likely corresponds to a low disease activity state as it allows for residual activity in some items. ${ }^{49}$ On the other hand, there is sufficient indirect evidence to suggest that in axial SpA and PsA, progression of damage is most strongly inhibited in states of remission/ inactive disease; low disease activity including MDA also conveys good structural outcomes ${ }^{505255}$ and physical function is maximised in remission. ${ }^{52}$ This recommendation was voted for by $75 \%$ of the participants in the first ballot.

2. The treatment target should be individualised based on the current clinical manifestations of the disease; the treatment modality should be considered when defining the time required to reach the target. The first part of this recommendation constituted the previous point 2 ; the term 'according to' was just replaced by 'based on'. It was also suggested that the term 'current' was deleted or changed, since one treats 'active' disease; however, the group preferred to adhere to 'current', since rheumatologists would understand what was meant. In the course of the discussions, several task force members suggested to add a time aspect, since the T2T concept generally calls for timely adaptation of therapy if a treatment is insufficiently effective and that the target and the time to reach 
the target are related concepts. On the other hand, the time point at which one can discern a good from a minor or no response differs depending on the drugs used (eg, shorter with non-steroidal anti-inflammatory drugs) than biologic (b) DMARDs or methotrexate). Thus, an interim proposal for this recommendation read: 'The treatment target and the time to reach the target should be individualised based on the current clinical manifestations of the disease and the treatment modality'. The opinion was then expressed that the target and the time to reach the target, while related, constituted separate concepts and, therefore, should be separated. With respect to timelines, treatment with DMARDs should show significant improvement within 3 months and attainment of the target within 6 months. These considerations resulted in the present version which attained a $94.4 \%$ approval.

3. Clinical remission/inactive disease is defined as the absence of clinical and laboratory evidence of significant disease activity. This recommendation, which defines item 1, ultimately remained almost unchanged compared with 2012, but three discussion points were raised. First, it was suggested to exclude the need for laboratory evidence in the definition, because MDA, and also clinical DAPSA, ${ }^{25}$ did not include $\mathrm{C}$ reactive protein (CRP) or erythrocyte sedimentation rate (ESR) in their formulae and were still associated with good outcomes. The opposite view related to the fact that APR levels were significantly associated with progression of damage both in PsA and axial SpA, 3856 and therefore should not be excluded from assessment of disease activity. Moreover, APRs are the only objective measure of articular or spinal disease activity (especially in axial $\mathrm{SpA}$ ) and reflect the same dimension as activity of arthritis or of spondylitis. It is noteworthy that this recommendation refers to 'clinical remission/inactive disease', in other words, it does not call for remission/inactive disease by imaging techniques such as sonography or MRI. Nevertheless, both DAPSA remission and a Boolean remission definition focusing on musculoskeletal items, but not MDA or CPDAI, were associated with minimal sonographic activity in PsA. ${ }^{5758}$ Finally, the question was raised whether having the concept of remission was necessary or rather the terms inactive disease or minimal disease activity would be sufficient. However, in the course of the discussion several participants mentioned that the concept of remission was essential for rheumatic diseases, since it implies a cure-like state with no further progression of damage; importantly in this context, damage is associated with active joint or spinal disease, potentially even progressing slightly in low disease activity. ${ }^{395052}$ As a result of these deliberations, this recommendation was approved in the first ballot by $88.9 \%$ of the task force members.

4. Low/minimal disease activity may be an alternative treatment target. Stringent remission, as defined in point 3, may be difficult to achieve in many patients in clinical practice, especially in those with long-standing disease or substantial comorbidities. The discussion focused on the need to understand the potential failure to attain a state named remission, since this failure could be a consequence of the instruments used; in particular, including physical function in an index may preclude attaining remission in those patients in whom function is severely impaired due to significant damage. This has been seen in ankylosing spondylitis (AS), where ASAS partial remission includes function ${ }^{36}$ and is less frequently achieved than ASDAS inactive disease. ${ }^{59}$
Of note, ASDAS terminology refers to low disease activity as moderate disease activity, since the disease activity states include 'very high' in addition to 'high'; this should be considered when interpreting ASDAS data or using ASDAS in practice. It was then discussed that the Health Assessment Questionnaire Disability Index (HAQ) was just one item of several in the MDA criteria set or other indices, such as the CPDAI or GRACE, and patients could fulfil the other elements. However, allowing only six items to be achievable in the MDA, for example, may still decrease the chances of reaching a satisfactory status. MDA was applied as target in TICOPA, an open-label but controlled clinical trial, which allowed the SLR to adjudicate a high level of evidence (2b) to the trial and to this item with a grade of recommendation of $\mathrm{B}^{10}$ (table 3 ). All task force members acknowledged the importance of this first-in-disease randomised strategic trial. By corollary, since low disease activity is an alternative target to remission, higher disease activity states are unacceptable, unless these are due to explicit patient preferences or reduction of disease activity is precluded by comorbidities or risks. Thus, ultimately the agreement on the treatment target should be based on a shared decision making between clinicians and patients. This recommendation achieved a $97.2 \%$ approval.

5. Disease activity should be measured on the basis of clinical signs and symptoms, and acute phase reactants. Initially, the question was raised if imaging should also be included when speaking of disease activity assessments. However, this suggestion was refuted because there are no data justifying the use of imaging in follow-up as yet and it is not feasible to perform MRI every few weeks in axial SpA. In early RA, following patients using ultrasound to target sonographic remission was not superior to clinical follow-up and a waste of healthcare resources. ${ }^{6061}$ In light of the deliberations on point 3, no further discussions on the use of APRs in clinical practice ensued. This item remained unchanged compared with the 2012 version and achieved a $88.9 \%$ majority vote.

6. Validated measures of musculoskeletal disease activity and assessment of cutaneous and/or other relevant extra-articular manifestations should be used in clinical practice to define the target and to guide treatment decisions; the frequency of the measurements depends on the level of disease activity. This item is related to recommendation 10 of the 2012 version. However, it was one of the recommendations, which had been separately developed for axial $\mathrm{SpA}$, peripheral SpA and PsA. Since all three recommendations had many components in common, it was deemed appropriate to combine them into a single recommendation. Previously, this item partly referred to specific instruments, such as Bath Ankylosing Spondylitis Disease Activity Index (BASDAI) ${ }^{62}$ plus APRs or ASDAS, with or without measures of function such as Bath Ankylosing Spondylitis Functional Inde ${ }^{63}$, for axial SpA, or 'arthritis, dactylitis, enthesitis, axial disease' and 'cutaneous manifestations' for PsA. It was felt that the aspect of specific scores should be separated from the more general parts and that extra-articular manifestations should be considered in PsA and in peripheral and axial $\mathrm{SpA}$, given the potential for wideranging clinical manifestations, by which they are also classified. ${ }^{64}$ Thus, this general comment was expanded and somewhat reworded to include cutaneous and 'other relevant extra-articular manifestations', indicating that eye (uveitis) and bowel (IBD) manifestations should also be considered, in line with overarching principle C. The 


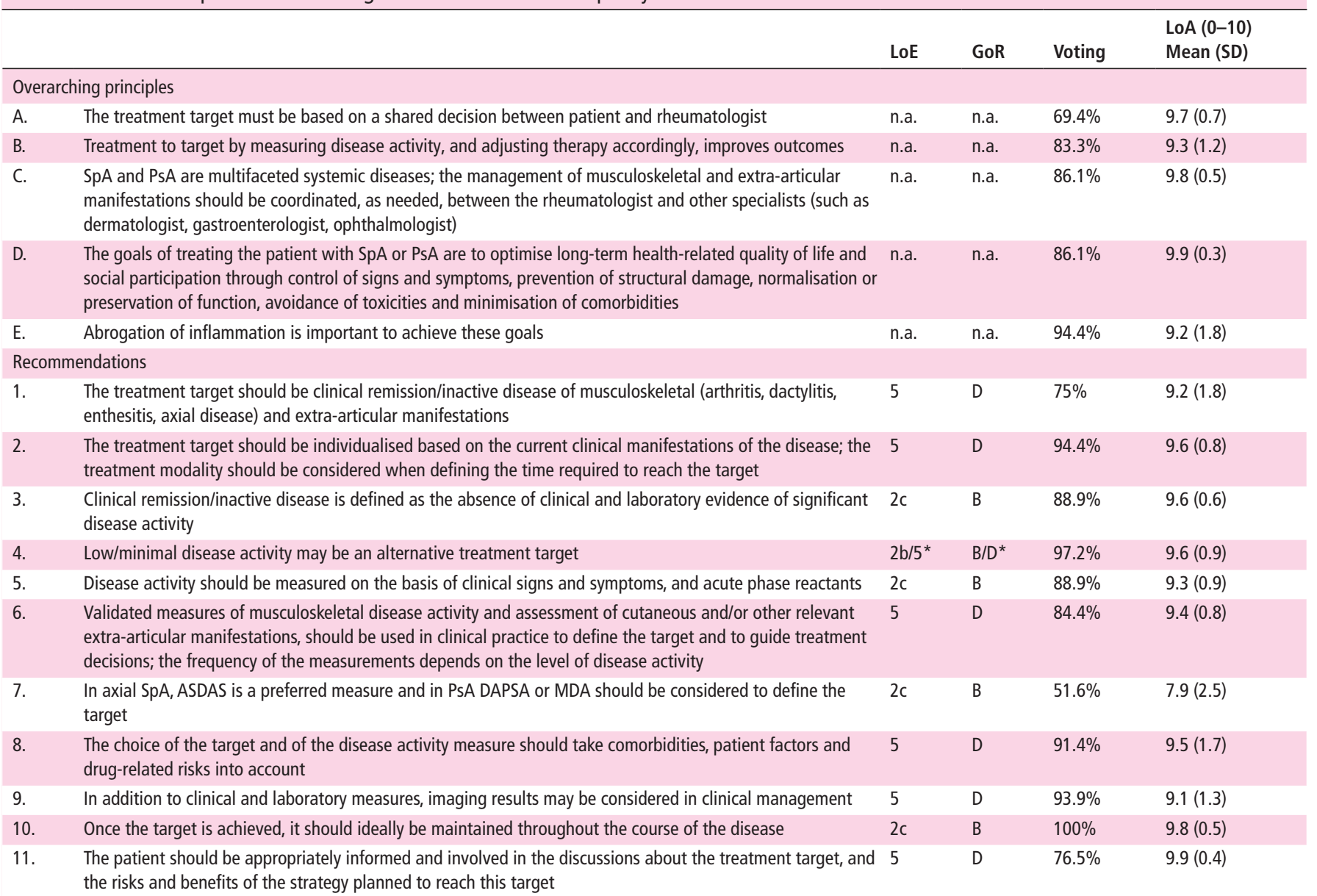

*2b (A) for PsA, 5 (D) for axial SpA.

ASDAS, Ankylosing Spondylitis Disease Activity Score; DAPSA, Disease Activity index for PSoriatic Arthritis; LoA, level of agreement among the task force members (mean (SD); LoE, level of evidence and GoR, grade of recommendation, both according to the Oxford Centre of Evidence-Based Medicine (evidence as provided by clinical trials underlying the recommendation); MDA, Minimal Disease Activity; n.a., not applicable; PsA, psoriatic arthritis; SpA, spondyloarthritis.

2012 recommendation included the notion that the validated measures should also be 'documented regularly'; this was now omitted, but it should be part of standard of care in the context of the T2T recommendations that results of measuring disease activity must be recorded in the patients' charts. Also, in line with the previous version, it is recommended that patients with high disease activity should be rheumatologically evaluated at short intervals (every 1-3 months), while those who achieved the treatment target could be followed less frequently, such as every 6-12 months; hence, the dependence on disease activity. As ultimately worded, this recommendation obtained $84.4 \%$ of the votes.

7. In axial SpA, ASDAS is a preferred measure and in PsA DAP SA or MDA should be considered to define the target. This bullet point addresses the clinical assessment of axial $\mathrm{SpA}$ and PsA, which was a focus of intensive debates during the consensus meeting. The discussion addressed both SpA subentities separately for some time, although there was some intermix in the course of these deliberations.

Regarding axial SpA, the 2012 version had suggested the assessment of ASDAS and/or BASDAI plus CRP. However, it was mentioned that the discrimination of BASDAI plus CRP is not as good as that of ASDAS and a model with ASDAS versus one including BASDAI and CRP was more closely correlated with syndesmophyte formation. ${ }^{65}$ Indeed, ASDAS is more associated with various biomarkers of inflammation than BASDAI ${ }^{66}$ and correlates better with MRI changes. ${ }^{67}$ When ASAS partial remission was brought into the discussion, it became clear that, as stated before, it comprises physical function which is primarily an outcome variable and partly dependent on spinal damage, making it less responsive and discriminative than ASDAS. However, colleagues from the USA felt that the requirement of a laboratory measure (CRP) in the ASDAS could decrease feasibility in the USA in daily clinical practice, since laboratory testing may not always be possible on or sometimes even close to the date of the visits. It was counter-argued that CRP from the previous visit could be used when the patient was in the office and ASDAS could be corrected once the new laboratory evaluation was available, or a CRP could already be collected before the office visit, but this may not be generally feasible. Moreover, recommendation 3 states that remission should also be defined by laboratory markers, so a CRP value should be obtained to be able to comply with this recommendation.

After this discussion on assessment of axial SpA, scoring systems for disease activity of PsA became again a heavily debated topic. It was restated by some members that from a methodological viewpoint composite measures should 
ideally be unidimensional. ${ }^{28} 68$ This view was opposed by others stating that a multidimensional measure such as CPDAI and PASDAS allowed the physician to see individual jmgdomain responses while providing a comprehensive measure of inflammatory disease activity. The discussion continued with the question, why one needed to bring them together and then still look at them separately rather than leaving them separate; to calculate the composite scores one must have the individual component scores. Those suggesting separate assessments mentioned that not all drugs have similar efficacy on all domains, based on the genetic and pathogenic heterogeneity of the disease $^{69}$; consequently, a drug may convey a good result when using a multidimensional score due to an excellent effect on the skin, but lack efficacy on an individual aspect of the disease, such as the joints. They further asked if a drug should be approved for PsA on the basis of results of such a composite measure. The dermatologists among the task force members mentioned that fumarates, which are primarily used in Europe, have significant effects on the skin and only modest benefit on the articular disease. ${ }^{70} 71$ Similarly, cyclosporine has only little effect on arthritis ${ }^{72}$ and inhibition of interleukin-17 has similar efficacy as tumour necrosis factor-inhibition on joints but a more profound effects on the skin. ${ }^{73}$ Additional information on PsA scores comes from a post hoc analysis of the Psoriasis Randomised Etanercept STudy in subjects with psoriatic Arthritis (PRESTA) trial in which a $100 \mathrm{mg}$ weekly dose of etanercept was compared with $50 \mathrm{mg}$ weekly. At 12 though not at 24 weeks the CPDAI but not the DAPSA distinguished treatment response between the two doses. ${ }^{74}$ In the original trial, however, no significant difference of articular, dactylitis and enthesitis scores was observed between the doses at any time point; only the Psoriasis Area and Severity Index (PASI) differentiated between the doses at 12 but not 24 weeks. ${ }^{75}$ Etanercept is approved at $50 \mathrm{mg}$ weekly for PsA and at $100 \mathrm{mg}$ weekly (for the first 12 weeks) for psoriasis. Notably management recommendations by both GRAPPA and EULAR suggest different treatment algorithms when patients present with a predominance of arthritis, enthesitis or skin involvement. ${ }^{23}$ Generally T2T recommendations are not dealing with recommendations on individual therapies but, as stated before, are of generic nature; the treatment-related considerations addressed here have been specifically mentioned during the meeting or in the course of manuscript development in relation to the validity of instruments used to assess PsA activity and are thus pertinent for the general aspects of the discussion and not to make any therapeutic inferences.

Importantly, it was generally agreed that all manifestations of PsA needed to be assessed and that for each of the domains validated measures existed, but there was disagreement whether to bring them together into one score or evaluate them separately. One task force member stated that recommendations are also important to educate rheumatologists to include assessment of the skin and other manifestations when dealing with patients with PsA; dermatologists should at least also enquire about joint manifestations. Recommendations should provide a goal for attaining better disease control and should not be based solely on feasibility considerations. Others asked if rheumatologists should then be forced to perform detailed skin and other assessments, given that their main focus is the arthritic component and that scores needed to be feasible in light of the time constraints in clinical practice that have been identified as factors limiting T2T. Some rheumatologists may prefer to cooperate with a dermatologist when making treatment decisions for patients with more severe skin disease rather than making their own decisions, in line with overarching principle C.

Feasibility was seen as an important aspect of the applicability of a score ${ }^{23}$ and from this perspective separate assessment of individual domains (musculoskeletal and cutaneous), in line with items 1 and 6 of the recommendations, was regarded by some to be more feasible and informative than combining them in a global composite measure. Furthermore, the question whether evidence existed for the contribution of skin involvement, or other measures that are not joint-related, to progression of joint damage in patients with PsA is unresolved; however, quality of life is strongly influenced by both musculoskeletal and skin disease. Regarding skin involvement, the dermatologists mentioned that a PASI of 1 or a Bosy Surface Area (BSA) of 3 , as would be compatible with MDA or even fulfilment of very low disease activity (VLDA) criteria, that is, seven out of the seven components of the MDA, was less relevant than the contextual aspects: a BSA of 1 , being equal to one palm of overall skin involvement, would be seen differently depending on the localisation of the skin affection (eg, face) and the patients' illness perception. However, the BSA thresholds of 1 and 3 are in line with the new T2T recommendations in psoriasis developed by the National Psoriasis Foundation. ${ }^{76}$ A proposal to revalidate the DAPSA with the addition of a skin component was contested in light of the methodological aspect of unidimensionality. Likewise, the suggestion to revalidate MDA by deleting skin involvement and HAQ and adding CRP was countered by those who felt that skin should be included for face validity considering a construct of overall disease activity and that MDA had been used in the TICOPA trial as originally constructed.

At some point, the discussion was stopped because all arguments had already been heard with no resolution of the methodological dissent. Given this difference of opinions, it was suggested that further research needed to be performed in PsA. In the field of axial SpA, the situation was much clearer, even though the evidence was less direct. Therefore, the way was paved for voting just on axial SpA. Thus, the initial ballot involved only the first part of the current recommendation. However, the first proposal stating that ASDAS was 'the' preferred measure attained only $59.4 \%$ of the votes, rather than the necessary $75 \%$. The ensuing discussion focused around the fact that a recommendation to use the ASDAS did not imply that it was mandatory to use the ASDAS and it was proposed to replace "“the" preferred measure' by “"a" preferred measure'.

At this point in time, a task force member voiced the disappointment regarding the sole focus on instruments for axial $\mathrm{SpA}$, in light of the significant advancements in the PsA field since the days of the last T2T consensus. It was propositioned to also include PsA-specific assessments in the recommendation. It was remarked that neither had a strategic trial been performed in axial SpA hitherto nor had the ASDAS been used in such strategy; therefore, it was felt that the overall levels of information for axial SpA and PsA were not so disparate as to justify focusing on axial $\mathrm{SpA}$ alone. It was further argued that the only strategic trial published in the wide field of SpA had been performed in PsA, using 
MDA as an anchor for advancing therapy, ${ }^{49}$ and that, just as much as ASDAS, both the continuous DAPSA (focusing on joint involvement) and MDA (a binary measure of disease state covering important domains of PsA including joints, skin and entheses) had been shown to have construct validity and were easy to perform in clinical practice. MDA defines a state; DAPSA allows definition of all disease activity states as well as levels of response to treatment. ${ }^{77}$ It was further stated that several items of the research agenda developed in 2012 (validation of scores, definition of disease activity states, response criteria, remission definition, therapeutic strategic trial $)^{1}$ had been fulfilled for PsA and that, therefore, indeed the focus should not only be on axial SpA.

After this plea, the second part of the current recommendation was proposed, but attained only $53.1 \%$ of the votes. Subsequent proposals also failed to now achieve a two-thirds majority. In a final ballot, the wording as stated in the recommendation was accepted by a simple majority of $51.6 \%$ of the participants. Of note, $>70 \%$ of the task force members assigned a level of agreement of 8 or higher in the anonymous vote after the meeting (see below).

8. The choice of the target and of the disease activity measure should take comorbidities, patient factors and drug-related risks into account. This recommendation is similar to item 6 in 2012. An interim proposal read: 'Comorbidities, patient factors and drug characteristics including risks should be considered when choosing the target and interpreting disease activity scores and the level of the target; drug characteristics including risks, should also be taken into account'. The discussion centred around the need to incorporate 'drug characteristics including risks', since drug-related risks would not influence the choice of the instrument but rather only of the target. The term patient factors refers to patient preferences or individual patient situations, such as a particular profession which may require a more or a less stringent treatment target. The question arose if patient input should also be addressed here, but it was argued that this aspect was already comprised in the overarching principles. Also, some felt that the recommendation was quite lengthy. Nevertheless, a ballot on the interim version took place, but attained only a $68.6 \%$ rather than a $75 \%$ majority. After further debates and reformulation attempts, the recommendation as now worded achieved a $91.4 \%$ majority.

9. In addition to clinical and laboratory measures, imaging results may be considered in clinical management. This is a new recommendation which relates to previous item 9 from the common trunk and the various items 11 from the specific recommendations approved in 2012. The part on 'functional impairment, extra-articular manifestations, comorbidities and treatment risks' was deleted from previous bullet point 9, since it was addressed in other items. The portion on 'clinical and laboratory measures' was reworded and brought to the front of the recommendation, since these measures should be the main focus of assessment. Of note, the term imaging results relates to all imaging modalities, conventional radiography, MRI and sonography, in line with what had been stated in points 9 and 11 in 2012. While imaging is not recommended as a target, it may assist where there is doubt if a target has been reached (ie, if the target was not reached because of inflammation or other reasons). This recommendation, as a replacement of previous numbers 9 and 11, achieved a 93.9\% majority.
10. Once the target is achieved, it should ideally be maintained throughout the course of the disease. This recommendation is almost identical to no. 7 from 2012 version. It was deemed a logical consequence of the items related to attainment of the target and there was almost no discussion-100\% of the participants voted for this wording.

11. The patient should be appropriately informed and involved in the discussions about the treatment target, and the risks and benefits of the strategy planned to reach this target. This recommendation is identical to no. 8 of the 2012 version. Some slight rewordings did not appeal to the task force. Also, a discussion on the addition of the term 'treatment goals' rather than 'treatment target' took place, but it was ultimately agreed that the term 'target' was used throughout the document and should not be weakened. The current wording was approved by $76.5 \%$ of the task force members.

After the task force meeting, the overarching principles and specific recommendations were placed into a logical sequence and then subjected to anonymised electronic voting regarding the levels of agreement. These results, together with the levels of evidence and strengths of recommendations are presented next to each item (table 3). The task force members' LoA with the overarching principles ranged from 9.2 to 9.9 out of $0-10$, reflecting a high level of agreement. Likewise, the LoA with 10 of the individual recommendations ranged from 9.1 to 9.9. Only recommendation 7 reached a lower LoA, namely 7.9. It is noteworthy that two participants did not agree at all (score of 0 ), nine gave scores of $5-7$, but the majority $(70.3 \%)$ still bestowed scores between 8 and 10 (13 scored 10) to this recommendation.

The updated recommendations are also captured in an algorithm (figure 2).

\section{Research agenda}

While several points of the previous research agenda have been answered now, other items remained open and new research questions arose. These are listed in table 4.

\section{DISCUSSION}

T2T has been widely used for several decades to improve outcomes of non-rheumatic diseases. ${ }^{78-80}$ More recently, T2T strategies have also entered the field of rheumatology and T2T recommendations for RA were published at the beginning of this decade. ${ }^{81}$ In the interim, T2T recommendations have also been developed for gout and systemic lupus erythematosus (SLE). ${ }^{82} 83$ In 2012, an international task force had also developed T2T recommendations for treating SpA, including AS and PsA. ${ }^{1}$

While treatment recommendations should be based on available evidence, neither the T2T recommendations for gout or SLE nor the previous ones for SpA derived from clear evidence showing the superiority of such steered treatment approach. They arose from a strong belief that this would be the case, with support from indirect information. Moreover, the recommendations elicited awareness of an important unresolved question and a pertinent research agenda. This agenda was indeed published as part of the SpA recommendations and many research questions raised several years ago have now been answered.

For example, one research question related to the validation and definition of disease activity and response criteria. Subsequently, several composite measures were validated, ${ }^{12}$ disease activity states defined and response criteria developed. ${ }^{77} \mathrm{~A}$ further quest was the definition of remission, which was also attained for PsA (remission) and axial SpA (inactive disease). ${ }^{77} 84$ 


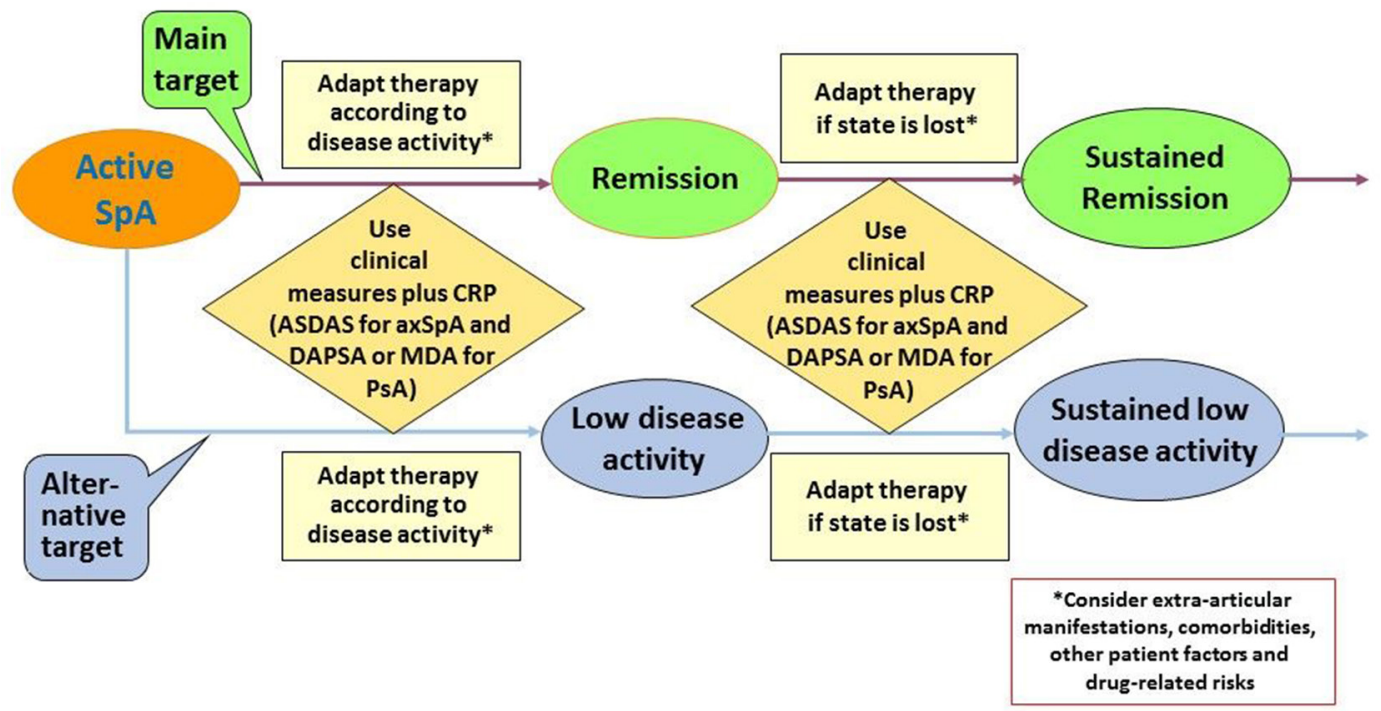

Figure 2 Algorithm based on the 2017 update of the treat-to-target recommendations for spondyloarthritis. axSpA, axial SpA; CRP, C-reactive protein; DAPSA, Disease Activity index for PSoriatic Arthritis; MDA, Minimal Disease Activity; PsA, psoriatic arthritis; SpA, spondyloarthritis.

The research question regarding the importance of including all domains of PsA or axial SpA in the remission definition is still unresolved. There are conflicting data on the magnitude of influence of psoriasis on physical function as measured by the HAQ. ${ }^{85} 86$ Yet another research question related to differences between low disease activity and remission in terms of outcomes which was clearly the case. ${ }^{52} 87$ Likewise, the question regarding the relationship between disease activity and damage found a clear answer. ${ }^{385052}$ Finally, the pursuit of designing and performing a therapeutic trial comparing steered therapy aiming at remission or low disease activity with non-steered treatment was also completed in PsA. ${ }^{49}$

Thus, a large part of the research agenda posed in 2012 was addressed over the last few years; therefore, it was deemed timely to re-evaluate the recommendations. The committee went through at times lengthy discussions, but ultimately formulated 5 overarching principles and 11 recommendations, which received very high levels of agreement in a final anonymous ballot. Most importantly, while all recommendations developed in 2012 had a very low LoE and GoR (5 and D, respectively), 5 of the 11 recommendations in 2017 are now based on B grades of recommendation, a clear advancement in 5 years.

Another aspect deserves mention: the 2012 task force originally planned to develop three separate sets of recommendations, one each for axial SpA (AS), PsA and peripheral SpA (such as reactive and IBD arthritis) and finally arrived at nine common and two additional separate recommendations for each of the SpA subsets. Now the task force did not even discuss separate recommendations

\begin{tabular}{|c|c|}
\hline Axial involvement in PsA & Do spinal and peripheral involvements respond similarly or differently? \\
\hline Enthesitis, dactylitis & $\begin{array}{l}\text { More data need to be attained on the response of dactylitis or enthesitis to different therapies when compared with arthritis and skin } \\
\text { disease. } \\
\text { How does dactylitis or enthesitis affect physical function, health-related quality of life, social participation or cardiovascular risk? } \\
\text { To what extent does their inclusion in composite measures increase or decrease validity and sensitivity to change? }\end{array}$ \\
\hline Skin involvement & $\begin{array}{l}\text { More data need to be attained on the response of psoriasis to different therapies when compared with arthritis and other musculoskeletal } \\
\text { symptoms. } \\
\text { How does skin involvement affect physical function or cardiovascular risk? } \\
\text { To what extent does its inclusion in composite measure increase or decrease validity and sensitivity to change? } \\
\text { To what extent do skin changes affect quality of life, work participation and social inclusion beyond the respective effects of arthritis and } \\
\text { other musculoskeletal manifestations? }\end{array}$ \\
\hline Imaging & $\begin{array}{l}\text { Is imaging useful for follow-up in axial SpA and PsA? } \\
\text { Should imaging remission be a treatment target in axial SpA and PsA? }\end{array}$ \\
\hline Functioning/disabillity & What is the impact of functioning/disability in composite measures developed for PsA? \\
\hline Strategic trials & Strategic trials in axial SpA and at least one additional strategic trial in PsA. \\
\hline Patient & Is outcome different when patients are informed in a structured way when compared with more general means of information? \\
\hline Harmonisation & Nomenclature should be harmonised—remission vs inactive disease; minimal disease activity vs low disease activity, etc. \\
\hline Structural damage & $\begin{array}{l}\text { Does achievement of the treatment target result into prevention or retardation of structural damage development in the spine/peripheral } \\
\text { joints in SpA? }\end{array}$ \\
\hline Biomarkers & We need better biomarkers of disease activity than CRP for both axial SpA and PsA. \\
\hline
\end{tabular}


for axial SpA, peripheral SpA and PsA, since all respective items 10 and 11 in 2012 were very similar, indeed. ${ }^{1}$ Thus, while 9 plus $2 \times 3$ recommendations had been developed in 2012, this committee arrived at a total of 11 rather than 15 points. While trials in patients with peripheral SpA other than PsA were not found in the SLR, it is noteworthy that DAPSA had originally been derived and validated in reactive arthritis. ${ }^{25}$

The wording of the overarching principles, for which no evidence was sought as they relate to very general conduct and treatment approaches, was more focused and the sequence slightly amended compared with the 2012 recommendations. Shared decision-making between patients and rheumatologists, recognition of the multiple facets of SpA, adjustment of therapy according to disease activity and targeting optimisation of health-related quality of life by abrogating inflammation continue to be their major aspects. Thus, the overarching principles remained essentially similar.

With respect to the individual recommendations, items 1-5 are very similar when compared with 2012. Targeting remission/inactive disease (item 1 ) and, as an alternative, low/ minimal disease activity (number 4 ) are the mainstays of treatment to target. Remission was defined as the absence of clinical and laboratory evidence of significant disease activity (item 3). Likewise, the need to individualise therapy in line with disease manifestations (number 2) and disease activity assessment by measuring clinical signs and symptoms as well as acute phase reactants (item 5) was upheld. The use of validated measures of musculoskeletal disease activity, but also of extra-articular manifestations, previously presented as the 10 th and 11 th recommendations, is now addressed as point 6 .

Item 7 is now more specific than previous item 10 in terms of the recommendation of specific instruments. For axial SpA, ASDAS is now more clearly highlighted as assessment tool. Some discussion arose around this instrument, since it comprises CRP which is often not immediately available in clinical practice, although it was clarified that a previous CRP measurement could be used until the new laboratory result became available. Moreover, recommendations no. 3 and 5 state that the target should include clinical and laboratory measures, which implies that CRP should be obtained irrespective of whether it is included in the ASDAS or kept separately. The focus on ASDAS in this recommendation puts the previous inclusion of BASDAI plus CRP into the background, which also respects the high discriminative capacity and sensitivity to change of ASDAS. ${ }^{66}$

For PsA, DAPSA and MDA are now explicitly mentioned, although other instruments are not discounted, awaiting further evaluation. DAPSA includes CRP, but as it is unidimensional it focuses only on joint involvement, incorporating patient global and pain assessments, but does not include a measurement of skin abnormalities nor non-articular musculoskeletal involvement; these manifestations need to be separately evaluated, as mentioned in items 1 and 6. MDA comprises peripheral arthritis, enthesitis and skin involvement, but since it does not include a laboratory variable (as addressed in items 3 and 5), this should be separately evaluated. It is the only target evaluated in a T2T study to date. ${ }^{49}$ There is concern about the inclusion of physical function in MDA as this may reflect damage as well as activity and thus be less appropriate for patients with longstanding disease and irreversible disability. Of note, MDA is a state and thus useful as a target. DAPSA allows one to all define states, includingremission or low disease activity. It constitutes a more PsA-specific joint-related measure than those applied in numerous pivotal clinical trials performed for the approval of new drugs and advancement of our treatment armamentarium, which used RA-derived assessments. Disease activity states have also been defined for the various multidimensional indices, such as CPDAI, GRACE and PASDAS. ${ }^{24} 88$

The subsequent three recommendations, items $8-10$, focus on the necessity to take comorbidities and risks of therapy into consideration, the possibility to consider using imaging tools in addition to clinical and laboratory assessments (not instead) and the importance of sustaining a good outcome, once achieved. The final point reiterates overarching principle A by addressing information on and discussion of the treatment approaches with the patient. Thus, in their totality, these recommendations are 'framed' by the basic aspect of thorough physician-patient interactions in the context of planning for and making any therapeutic decisions.

With the exception of one item, the level of agreement with the recommendations was generally very high, on average exceeding a level of 9 on a scale between 0 and 10 . Item 7 , which addressed specific tools, attained a somewhat lower level of agreement based on the various controversies around this issue as detailed previously. Nevertheless, even this recommendation achieved a mean level of agreement of almost 8 (out of 10), corroborating the decision made by the task force. However, it should be acknowledged that the task force did not reach agreement about the use of unidimensional versus multidimensional instruments for assessing disease activity in PsA. In contrast, the unidimensional approach to evaluate disease activity in axial $\mathrm{SpA}$, which can also exhibit multiorgan involvement although less frequently than PsA, was not disputed.

Of particular importance, the current recommendations do not address any specific type of treatment but rather deal with a general approach to treating $\mathrm{SpA}$; management recommendations, in contrast, deal with specific drugs for particular situations and have been specifically developed by respective committees, focusing on differences in management depending on the predominance of activity in specific disease domains. ${ }^{2-4}$ The current task force comprised a large number of experts which included several patients and a health professional. Among the rheumatologists, all had experience in the treatment of axial and peripheral SpA and most even had clinical trial experience. The development of the recommendations adhered to the EULAR SOPs for developing recommendations $^{11}$ and the recommendations are aimed at healthcare providers and patients as well as at clinical trialists, regulators and hospital or health insurance administrators. Also, a new research agenda has been developed.

In summary, an update of recommendations to treat SpA to target is presented based on new evidence accrued over the past 5 years. These recommendations are summarised in a Table, but all textual explanations are part and parcel of the recommendations. They are also depicted in a simple algorithm presented in figure 2. Adhering to these recommendations may significantly improve outcomes in patients with axial and peripheral SpA and PsA.

\section{Author affiliations}

${ }^{1}$ Division of Rheumatology, Department of Medicine 3, Medical University of Vienna, Vienna, Austria

${ }^{2}$ 2nd Department of Medicine, Hietzing Hospital, Vienna, Austria

${ }^{3}$ Health Consult, Vienna, Austria

${ }^{4}$ Rheumazentrum Ruhrgebiet, Ruhr-University Bochum, Herne, Germany

${ }^{5}$ Department of Rheumatology, Paris Descartes University, Paris, France

${ }^{6}$ Department of Rheumatology, St Vincent's University Hospital, Dublin, Ireland

${ }^{7}$ Division of Rheumatology, University of Toronto, Toronto, Ontario, Canada

${ }^{8}$ Division of Rheumatology, University of California, San Diego, CA, USA

${ }^{9}$ Amsterdam Rheumatology \& Immunology Center, Amsterdam, The Netherlands 
${ }^{10}$ Division of Rheumatology Research, Swedish-Providence St. Joseph Health System, University of Washington, Seattle, WA, USA

${ }^{11}$ Department of Gastroenterology, Infectiology and Rheumatology, Campus Benjamin Franklin, Charité Universitätsmedizin Berlin, Berlin, Berlin, Germany

${ }^{12}$ Section for Outcomes Research, Center for Medical Statistics, Informatics, and Intelligent Systems, Medical University of Vienna, Vienna, Austria

${ }^{13}$ Department of Medical Humanities, VU University Medical Centre, Amsterdam, The Netherlands

${ }^{14}$ Neil Betteridge Associates, UK

${ }^{15}$ Ghent University Hospital, Ghent, Belgium

${ }^{16}$ Department of Orthopaedics, Rheumatology and Musculoskeletal Sciences, University of Oxford, Oxford, UK

${ }^{17}$ Leeds Institute of Rheumatic and Musculoskeletal Medicine, Leeds, UK

${ }^{18}$ Department of Medicine, University of California, San Francisco, CA, USA

${ }^{19}$ Department of Rheumatology, UPMC Univ Paris 06, GRC-UPMC 08 (EEMOIS); AP-

HP, Pitié Salpêtrière Hospital, Paris, France

${ }^{20}$ Institute of Molecular Medicine, University of Leeds, Leeds, UK

${ }^{21}$ Seayn Medical, Voorschoten, The Netherlands

${ }^{22}$ Department of Rheumatology, Diakonhjemmet Hospital, Oslo, Norway

${ }^{23}$ University Health Network and University of Toronto, Toronto, Ontario, Canada

${ }^{24}$ University of Glasgow, College of Medical Veterinary and Life Sciences, Glasgow, UK

${ }^{25}$ A.DI.PSO. (Associazione per la Difesa degli Psoriasici)—PE.Pso.POF (Pan European Psoriasis Patients' Organization Forum), Rome, Italy

${ }^{26}$ Centre for Rheumatology \& MRC Centre for Neuromuscular Diseases, University College London, London, UK

${ }^{27}$ Division of Rheumatology, Center for Clinical Epidemiology and Biostatistics, Perelman School of Medicine, University of Pennsylvania, Pennsylvania, PA, USA

${ }^{28}$ German Rheumatism Research Centrer, Berlin, Germany

${ }^{29}$ Allergy, Immunology and Rheumatology Division, University of Rochester Medical Center Rochester, New York, NY, USA

${ }^{30}$ Division of Internal Medicine and Rheumatology, Klinikum Bielefeld, Bielefeld, Germany

${ }^{31}$ Department of Dermatology, Medical University of Vienna, Vienna, Austria

${ }^{32}$ Department of Dermatology, Erasmus Medical Center, Erasmus University, Rotterdam, The Netherlands

${ }^{33}$ Department of Rheumatology, Klinikum Bielefeld, Bielefeld, Germany

${ }^{34}$ Division of Rheumatology, University Hospitals Leuven, Leuven, Belgium

${ }^{35}$ Department of Rheumatology, Leiden University Medical Center, Leiden, The

Netherlands

Correction notice This article has been corrected since it published Online First. The figure 2 legend has been corrected.

Acknowledgements This activity was made possible by a grant from AbbVie tothe Medical University of Vienna. No company representative had any influence onthe procedure or content nor was any company representative present at any of themeetings or received the manuscript before submission.

Contributors All authors have contributed to the development of the recommendations and the manuscript.

Competing interests DA served as a consultant and/or speaker for Abbvie, Astra-Zeneca, BMS, Janssen, Medac, MSD, Pfizer, Roche, UCB and received grant support from BMS. XB has served as consultant and/or speaker for Abbvie, BMS, Celgene, Chugai, Janssen, Novartis, Pfizer, UCB. NB has received consultancy fees for work commissioned by Grünenthal, Lilly, Janssen, PfizerLaura Coates has received research funding from Abbvie and Janssen and honoraria from Abbvie, Amgen, BMS, Celgene, Janssen, Lilly, MSD, Novartis, Pfizer, Sun Pharma, UCBMaxime Dougados has participated as a speaker in symposia or as an advisor in boards organized by Pfizer, Abbvie, Ucb, Merck, Amgen, Novartis, Lilly, Bms, Roche and his department has received research grants from Pfizer, Abbvie, Ucb, Merck, Amgen, Novartis, Lilly, Bms, Roche. Laure Gossec has received honoraria or research funding from Abbvie, BMS, Celgene, Janseen, MSD, Novartis, Pfizer, Roche and UCB. PE has undertaken clinical trials and provided expert advice to Pfizer, MSD, Abbvie, BMS, UCB, Roche, Novartis, Samsung, Sandoz and Lilly. OF reports grants and personal fees from Novartis, personal fees from Pfizer, personal fees from Lilly, personal fees from Cellgene, grants and personal fees from Abbvie, personal fees from Janssen, personal fees from UCB, outside the submitted work. AK has served as consultant and/or performed clinical research for Abbvie, Amgen, Celgene, Janssen, Novartis, UCB. PMM has received consultancy/speaker's fees from AbbVie, Centocor, Janssen, Merck, Novartis, Pfizer and UCB. AM has received honoraria from Abbvie, MSD and UCBDP has received Grant/research support from: AbbVie, MSD, Novartis, Pfizer, has honoraria/speaker fees from AbbVie, BMS, Boehringer, Janssen, Lilly, MSD, Novartis, Pfizer, Roche, and UCB. MR has received honoraria/ consultancies from Abbvie, BMS, Celgene, Chugai/Roche, Janssen, MSD, Novartis, Pfizer, UCB. JS has received grant support from and/or provided expert advice to Abbvie, Amgen, Astra-Zeneca, BMS, Boehringer-Ingelheim, Celgene, Celltrion, Gilead, Glaxo, Iltoo, Janssen, Lilly, Pfizer, MSD, Roche, Samsung, Novartis-Sandoz, UCB. TS has received honoraria from
Abbvie, Janssen, MSD, Novartis and Roche and grant support from Abbvie. FVB has received speaker and/or consultancy fees from AbbVie, Celgene, Janssen, Lilly, MSD, Novartis, Pfizer and UCB. DH has received consulting fees Afrom bbVie, Amgen, Astellas, AstraZeneca, BMS, Boehringer Ingelheim, Celgene, Daiichi, Eli-Lilly, Galapagos, Gilead, Glaxo-Smith-Kline, Janssen, Merck, Novartis, Pfizer, Regeneron, Roche, Sanofi, Takeda, UCB, and is Director of Imaging Rheumatology bv. MW has received consulting fees for lectures or advisory board meetings from Abbvie, BMS, Celgene, Eli Lilly, Novartis and Roche.

Provenance and peer review Not commissioned; externally peer reviewed.

Open Access This is an Open Access article distributed in accordance with the Creative Commons Attribution Non Commercial (CC BY-NC 4.0) license, which permits others to distribute, remix, adapt, build upon this work non-commercially, and license their derivative works on different terms, provided the original work is properly cited and the use is non-commercial. See: http://creativecommons.org/ licenses/by-nc/4.0/

(c) Article author(s) (or their employer(s) unless otherwise stated in the text of the article) 2018. All rights reserved. No commercial use is permitted unless otherwise expressly granted.

\section{REFERENCES}

1 Smolen JS, Braun J, Dougados M, et al. Treating spondyloarthritis, including ankylosing spondylitis and psoriatic arthritis, to target: recommendations of an international task force. Ann Rheum Dis 2014;73:6-16.

2 Gossec L, Smolen JS, Ramiro S, et al. European League against Rheumatism (EULAR) recommendations for the management of psoriatic arthritis with pharmacological therapies: 2015 update. Ann Rheum Dis 2016;75:499-510.

3 Coates LC, Kavanaugh A, Mease PJ, et al. Group for Research and Assessment of Psoriasis and Psoriatic Arthritis 2015 treatment recommendations for Psoriatic Arthritis. Arthritis Rheumatol 2016:68:1060-71.

4 van der Heijde D, Ramiro S, Landewé R, et al. 2016 update of the ASAS-EULAR management recommendations for axial spondyloarthritis. Ann Rheum Dis 2017;76:978-91.

5 Warram JH, Manson JE, Krolewski AS. Glycosylated hemoglobin and the risk of retinopathy in insulin-dependent diabetes mellitus. N Eng/ J Med 1995;332:1305-6.

6 Smolen JS, Breedveld FC, Burmester GR, et al. Treating rheumatoid arthritis to target: 2014 update of the recommendations of an international task force. Ann Rheum Dis 2016;75.

7 Schoels M, Knevel R, Aletaha D, et al. Evidence for treating rheumatoid arthritis to target: results of a systematic literature search. Ann Rheum Dis 2010;69:638-43.

8 Stoffer MA, Schoels MM, Smolen JS, et al. Evidence for treating rheumatoid arthritis to target: results of a systematic literature search update. Ann Rheum Dis 2016:75:16-22

9 Schoels M, Braun J, Dougados M, et al. Treating axial and peripheral spondyloarthritis, including psoriatic arthritis, to target: results of a systematic literature search to support a consensus statement. Ann Rheum Dis 2014:73:238-42

10 OCEBM Levels of Evidence Working Group. Oxford Centre for Evidence-Based Medicine. The Oxford 2011 Levels of Evidence. 2011. Ref Type: Grant.

11 van der Heijde D, Aletaha D, Carmona L, et al. 2014 Update of the EULAR standardised operating procedures for EULAR-endorsed recommendations. Ann Rheum Dis 2015;74:8-13.

12 Helliwell PS, FitzGerald O, Fransen J, et al. The development of candidate composite disease activity and responder indices for psoriatic arthritis (GRACE project). Ann Rheum Dis 2013;72:986-91.

13 Smolen JS, Landewé R, Bijlsma J, et al. EULAR recommendations for the management of rheumatoid arthritis with synthetic and biological disease-modifying antirheumatic drugs: 2016 update. Ann Rheum Dis 2017;76:960-77.

14 Singh JA, Saag KG, Bridges SL, et al. 2015 American College of Rheumatology Guideline for the treatment of Rheumatoid Arthritis. Arthritis Care Res 2016;68:1-25.

15 Haraoui B, Smolen JS, Aletaha D, et al. Treating Rheumatoid Arthritis to target: multinational recommendations assessment questionnaire. Ann Rheum Dis 2011;70:1999-2002.

16 Solomon DH, Losina E, Lu B, et al. Implementation of Treat-to-Target in Rheumatoid Arthritis Through a Learning Collaborative: Results of a Randomized Controlled Trial. Arthritis Rheumatol 2017 [Epub ahead of print].

17 Vermeer M, Kuper HH, Bernelot Moens HJ, et al. Adherence to a treat-to-target strategy in early rheumatoid arthritis: results of the DREAM remission induction cohort. Arthritis Res Ther 2012:14:R254.

18 Grozdenović E, Allaart CF, van der Heijde D, et al. When rheumatologists report that they agree with a guideline, does this mean that they practise the guideline in clinical practice? results of the International Recommendation Implementation Study (IRIS). RMD Open 2016;2:e000221.

19 Haraoui B, Bensen W, Bessette L, et al. Treating rheumatoid arthritis to target: a canadian physician survey. J Rheumatol 2012;39:949-53.

20 Krüger K, Karberg K. [Treat-to-target from the perspective of office-based rheumatology]. Z Rheumatol 2011;70:664-9. 
21 Coates LC, Helliwell PS. Treating to target in psoriatic arthritis: how to implement in clinical practice. Ann Rheum Dis 2016;75:640-3.

22 Brouwers MC, Kho ME, Browman GP, et al. AGREE II: advancing guideline development, reporting and evaluation in health care. CMAJ 2010;182:E839-E842.

23 Boers M, Kirwan JR, Wells G, et al. Developing core outcome measurement sets for clinical trials: omeract filter 2.0. J Clin Epidemiol 2014;67:745-53.

24 Mumtaz A, Gallagher P, Kirby B, et al. Development of a preliminary composite disease activity index in psoriatic arthritis. Ann Rheum Dis 2011:70:272-7.

25 Schoels M, Aletaha D, Funovits J, et al. Application of the DAREA/DAPSA score for assessment of disease activity in psoriatic arthritis. Ann Rheum Dis 2010;69:1441-7.

26 Helliwell PS, Kavanaugh A. Comparison of composite measures of disease activity in psoriatic arthritis using data from an interventional study with golimumab. Arthritis Care Res 2014:66:749-56.

27 Coates LC, Fransen J, Helliwell PS. Defining minimal disease activity in psoriatic arthritis: a proposed objective target for treatment. Ann Rheum Dis 2010;69:48-53.

28 Crossman A. How to construct an index for research. $2017 \mathrm{http}: / /$ sociology about com/od/Research-Tools/a/index--ZB htm.

29 Benegas M, Muñoz-Gomariz E, Font $\mathrm{P}$, et al. Comparison of the clinical expression of patients with ankylosing spondylitis from Europe and Latin America.J Rheumatol 2012;39:2315-20.

30 Rudwaleit M, Haibel H, Baraliakos X, et al. The early disease stage in axial spondylarthritis: results from the german Spondyloarthritis Inception Cohort. Arthritis Rheum 2009:60:717-27.

31 Jabs DA, Nussenblatt RB, Rosenbaum JT. Standardization of Uveitis Nomenclature (SUN) Working Group. Standardization of uveitis nomenclature for reporting clinical data. Results of the First International Workshop. Am J Ophthalmol 2005;140:509-16.

32 Ravindran J, Cavill C, Balakrishnan C, et al. A modified sharp score demonstrates disease progression in established psoriatic arthritis. Arthritis Care Res 2010;62:86-91.

33 Aletaha D, Strand V, Smolen JS, et al. Treatment-related improvement in physical function varies with duration of rheumatoid arthritis: a pooled analysis of clinical trial results. Ann Rheum Dis 2008;67:238-43.

34 Aletaha D, Smolen J, Ward MM. Measuring function in rheumatoid arthritis: identifying reversible and irreversible components. Arthritis Rheum 2006:54:2784-92.

35 Husted JA, Tom BD, Farewell VT, et al. A longitudinal study of the effect of disease activity and clinical damage on physical function over the course of psoriatic arthritis: does the effect change over time? Arthritis Rheum 2007;56:840-9.

36 Sieper J, Rudwaleit M, Baraliakos X, et al. The Assessment of SpondyloArthritis international society (ASAS) handbook: a guide to assess spondyloarthritis. Ann Rheum Dis 2009;68 Suppl 2(Suppl 2):ii1-ii44.

37 van der Heijde D, Braun J, Dougados M, et al. Sensitivity and discriminatory ability of the Ankylosing Spondylitis Disease Activity score in patients treated with etanercept or sulphasalazine in the ASCEND trial. Rheumatology 2012;51:1894-905

38 Bond SJ, Farewell VT, Schentag CT, et al. Predictors for radiological damage in psoriatic arthritis: results from a single centre. Ann Rheum Dis 2007;66:370-6.

39 Cresswell L, Chandran V, Farewell VT, et al. Inflammation in an individual joint predicts damage to that joint in psoriatic arthritis. Ann Rheum Dis 2011;70:305-8.

40 van Leeuwen MA, van der Heijde DM, van Rijswijk MH, et al. Interrelationship of outcome measures and process variables in early rheumatoid arthritis. A comparison of radiologic damage, physical disability, joint counts, and acute phase reactants. J Rheumatol 1994;21:425-9.

41 Smolen JS, Van Der Heijde DM, St Clair EW, et al. Predictors of joint damage in patients with early rheumatoid arthritis treated with high-dose methotrexate with or without concomitant infliximab: results from the ASPIRE trial. Arthritis Rheum 2006:54:702-10.

42 van der Heijde DM, van't Hof MA, van Riel PL, et al. Validity of single variables and composite indices for measuring disease activity in rheumatoid arthritis. Ann Rheum Dis 1992;51:177-81

43 Tugwell P, Bombardier C. A methodologic framework for developing and selecting endpoints in clinical trials. J Rheumatol 1982;9:758-62.

44 Goldsmith CH, Boers M, Bombardier C, et al. Criteria for clinically important changes in outcomes: development, scoring and evaluation of rheumatoid arthritis patient and trial profiles. OMERACT Committee. J Rheumatol 1993;20:561-5.

45 Felson DT, Anderson JJ, Boers M, et al. American College of Rheumatology. preliminary definition of improvement in rheumatoid arthritis. Arthritis Rheum 1995;38:727-35.

46 Schuwirth LW, van der Vleuten CP. Programmatic assessment and Kane's validity perspective. Med Educ 2012;46:38-48.

47 Ofqual-Office of qualifications and examinations regulation U. Estimating the reliability of Composite scores. $2010 \mathrm{http} / / /$ dera ioe ac uk/1060/1/2010-02-01 composite-reliability pdf.

48 Stoffer MA, Smolen JS, Woolf A, et al. Development of patient-centred standards of care for rheumatoid arthritis in Europe: the eumusc.net project. Ann Rheum Dis 2014:73:902-5

49 Coates LC, Moverley AR, McParland L, et al. Effect of tight control of inflammation in early psoriatic arthritis (TICOPA): a UK Multicentre, open-label, randomised controlled trial. Lancet 2015;386:2489-98.
50 Ramiro S, van der Heijde D, van Tubergen A, et al. Higher disease activity leads to more structural damage in the spine in ankylosing spondylitis: 12-year longitudinal data from the OASIS cohort. Ann Rheum Dis 2014;73:1455-61.

51 Poddubnyy D, Protopopov M, Haibel H, et al. High disease activity according to the Ankylosing Spondylitis Disease Activity score is associated with accelerated radiographic spinal progression in patients with early axial spondyloarthritis: results from the GErman SPondyloarthritis Inception Cohort. Ann Rheum Dis 2016;75:2114-8.

52 Aletaha D, Alasti F, Smolen JS. Disease activity states of the DAPSA, a psoriatic arthritis specific instrument, are valid against functional status and structural progression. Ann Rheum Dis 2017;76:418-21.

53 Helliwell PS, Ruderman E. Natural history, prognosis and socio-economic aspects of psoriatic arthritis. In: Ritchlin C, Fitzgerald 0, eds. Psoriatic and reactive arthritis. Philadelphia: Mosby, 2007:29-36.

54 de Wit MP, Smolen JS, Gossec L, et al. Treating rheumatoid arthritis to target: the patient version of the international recommendations. Ann Rheum Dis 2011:70:891-5

55 Coates LC, Helliwell PS. Validation of minimal disease activity criteria for psoriatic arthritis using interventional trial data. Arthritis Care Res 2010;62:965-9.

56 Poddubnyy D, Haibel H, Listing J, et al. Baseline radiographic damage, elevated acutephase reactant levels, and cigarette smoking status predict spinal radiographic progression in early axial spondylarthritis. Arthritis Rheum 2012:64:1388-98.

57 Husic R, Gretler J, Felber A, et al. Disparity between ultrasound and clinical findings in psoriatic arthritis. Ann Rheum Dis 2014;73:1529-36.

58 Michelsen B, Diamantopoulos AP, Hammer HB, et al. Ultrasonographic evaluation in psoriatic arthritis is of Major importance in evaluating disease activity. Ann Rheum Dis 2016;75:2108-13.

59 Sieper J, van der Heijde D, Dougados M, et al. Efficacy and safety of adalimumab in patients with non-radiographic axial spondyloarthritis: results of a randomised placebo-controlled trial (ABILITY-1). Ann Rheum Dis 2013;72:815-22.

60 Dale J, Stirling A, Zhang R, et al. Targeting ultrasound remission in early rheumatoid arthritis: the results of the TaSER study, a randomised clinical trial. Ann Rheum Dis 2016;75:1043-50.

61 Haavardsholm EA, Aga AB, Olsen IC, et al. Ultrasound in management of rheumatoid arthritis: arctic randomised controlled strategy trial. BMJ 2016;354:14205.

62 Garrett S, Jenkinson T, Kennedy LG, et al. A new approach to defining disease status in ankylosing spondylitis: the Bath Ankylosing Spondylitis Disease Activity Index. $J$ Rheumatol 1994;21:2286-91.

63 Calin A, Garrett S, Whitelock H, et al. A new approach to defining functional ability in ankylosing spondylitis: the development of the Bath Ankylosing Spondylitis functional index. J Rheumatol 1994:21:2281-5.

64 Rudwaleit M, van der Heijde D, Landewé $\mathrm{R}$, et al. The development of Assessment of SpondyloArthritis International Society classification criteria for Axial spondyloarthritis (part II): validation and Final selection. Ann Rheum Dis 2009;68:777-83.

65 van der Heijde D, Lie E, Kvien TK, et al. ASDAS, a highly discriminatory ASAS-endorsed disease activity score in patients with ankylosing spondylitis. Ann Rheum Dis 2009:68:1811-8.

66 Pedersen SJ, Sørensen IJ, Hermann KG, et al. Responsiveness of the Ankylosing Spondylitis Disease Activity score (ASDAS) and clinical and MRI measures of disease activity in a 1-year follow-up study of patients with axial spondyloarthritis treated with tumour necrosis factor alpha inhibitors. Ann Rheum Dis 2010:69:1065-71.

67 Machado P, Landewé RB, Braun J, et al. MRI inflammation and its relation with measures of clinical disease activity and different treatment responses in patients with ankylosing spondylitis treated with a tumour necrosis factor inhibitor. Ann Rheum Dis 2012:71:2002-5.

68 Mokkink LB, Terwee CB, Knol DL, et al. The COSMIN checklist for evaluating the methodological quality of studies on measurement properties: a clarification of its content. BMC Med Res Methodol 2010;10:22.

69 FitzGerald $\mathrm{O}$, Haroon M, Giles JT, et al. Concepts of pathogenesis in psoriatic arthritis: genotype determines clinical phenotype. Arthritis Res Ther 2015;17:115

70 Balak DM, Fallah Arani S, Hajdarbegovic E, et al. Efficacy, effectiveness and safety of fumaric acid esters in the treatment of psoriasis: a systematic review of randomized and observational studies. Br J Dermatol 2016:175:250-62.

71 Peeters AJ, Dijkmans BA, van der Schroeff JG. Fumaric acid therapy for psoriatic arthritis. A randomized, double-blind, placebo-controlled study. Br J Rheumatol 1992:31:502-4.

72 Fraser AD, van Kuijk AW, Westhovens $R$, et al. A randomised, double blind, placebo controlled, multicentre trial of combination therapy with methotrexate plus ciclosporin in patients with active psoriatic arthritis. Ann Rheum Dis 2005;64:859-64.

73 McInnes IB, Mease PJ, Kirkham B, et al. Secukinumab, a human anti-interleukin-17A monoclonal antibody, in patients with psoriatic arthritis (FUTURE 2): a randomised, double-blind, placebo-controlled, phase 3 trial. Lancet 2015:386:1137-46.

74 FitzGerald O, Helliwell P, Mease P, et al. Application of composite disease activity scores in psoriatic arthritis to the PRESTA data set. Ann Rheum Dis 2012;71:358-62 
75 Sterry W, Ortonne JP, Kirkham B, et al. Comparison of two etanercept regimens for treatment of psoriasis and psoriatic arthritis: presta randomised double blind multicentre trial. BMJ 2010;340:c147.

76 Armstrong AW, Siegel MP, Bagel J, et al. From the Medical Board of the National Psoriasis Foundation: treatment targets for plaque psoriasis. J Am Acad Dermatol 2017;76:290-8.

77 Schoels MM, Aletaha D, Alasti F, et al. Disease activity in psoriatic arthritis (PsA): defining remission and treatment success using the DAPSA score. Ann Rheum Dis 2016;75:811-8.

78 Nathan DM, Genuth S, Lachin J, et al. Diabetes Control and Complications Trial Research Group. The effect of intensive treatment of diabetes on the development and progression of long-term complications in insulin-dependent diabetes mellitus. N Engl J Med 1993;329:977-86.

79 Hansson L, Zanchetti A, Carruthers SG, et al. Effects of intensive blood-pressure lowering and low-dose aspirin in patients with hypertension: principal results of the hypertension optimal treatment (HOT) randomised trial. HOT Study Group. Lancet 1998;351:1755-62

80 Ridker PM. Moving toward new statin guidelines in a post-JUPITER world: principles to consider. Curr Atheroscler Rep 2009:11:249-56.

81 Smolen JS, Aletaha D, Bijlsma JW, et al. Treating rheumatoid arthritis to target: recommendations of an international task force. Ann Rheum Dis 2010;69:631-7.

82 Kiltz U, Smolen J, Bardin T, et al. Treat-to-target (T2T) recommendations for gout. Ann Rheum Dis 2016;76:632-8.
83 van Vollenhoven RF, Mosca M, Bertsias G, et al. Treat-to-target in systemic lupus erythematosus: recommendations from an international task force. Ann Rheum Dis 2014;73:958-67.

84 Machado P, Landewé R, Lie E, et al. Ankylosing Spondylitis Disease Activity score (ASDAS): defining cut-off values for disease activity states and improvement scores. Ann Rheum Dis 2011;70:47-53.

85 Husted JA, Gladman DD, Long JA, et al. A modified version of the Health Assessment Questionnaire (HAQ) for psoriatic arthritis. Clin Exp Rheumatol 1995;13:439-43.

86 Sokoll KB, Helliwell PS. Comparison of disability and quality of life in rheumatoid and psoriatic arthritis. J Rheumatol 2001;28:1842-6.

87 Coates LC, Helliwell PS. Defining low disease activity States in Psoriatic Arthritis using novel Composite Disease Instruments. J Rheumatol 2016;43:371-5.

88 Helliwell PS, Waxman R. Modification of the Psoriatic Arthritis Disease Activity score (PASDAS). Ann Rheum Dis 2017:annrheumdis-2016-211010.

89 Lukas C, Landewé R, Sieper J, et al. Development of an ASAS-endorsed disease activity score (ASDAS) in patients with ankylosing spondylitis. Ann Rheum Dis 2009;68:18-24.

90 Anderson JJ, Baron G, van der Heijde D, et al. Ankylosing spondylitis assessment group preliminary definition of short-term improvement in ankylosing spondylitis. Arthritis Rheum 2001;44:1876-86.

91 Brandt J, Listing J, Sieper J, et al. Development and preselection of criteria for short term improvement after anti-TNF alpha treatment in ankylosing spondylitis. Ann Rheum Dis 2004;63:1438-44. 


\section{Correction: Treating axial spondyloarthritis and peripheral} spondyloarthritis, especially psoriatic arthritis, to target: 2017 update of recommendations by an international task force

Smolen JS, Schöls M, Braun J, et al. Treating axial spondyloarthritis and peripheral spondyloarthritis, especially psoriatic arthritis, to target: 2017 update of recommendations by an international task force. Ann of Rheum Dis 2017;77:3-17.

The affiliation for Douglas Veale has been corrected to Department of Rheumatology, University College Dublin, Ireland.

\section{6 \\ OPEN ACCESS}

Open Access This is an Open Access article distributed in accordance with the Creative Commons Attribution Non Commercial (CC BY-NC 4.0) license, which permits others to distribute, remix, adapt, build upon this work non-

commercially, and license their derivative works on different terms, provided the original work is properly cited and the use is non-commercial. See: http://creativecommons.org/licenses/by-nc/4.0/

(c) Article author(s) (or their employer(s) unless otherwise stated in the text of the article) 2018. All rights reserved. No commercial use is permitted unless otherwise expressly granted.

Ann Rheum Dis 2018;77:472. doi:10.1136/annrheumdis-2017-211734corr1 